\title{
ANALISIS KOMUNIKASI PADA PROGRAM PEMBERDAYAAN \\ MASYARAKAT (STUDI KASUS PROGRAM CORPORATE SOCIAL RESPONSIBILITY PENDIDIKAN PT. ADARO INDONESIA)
}

\author{
Dedi Setia Rahman \\ Email : dedisetiar@gmail.com \\ Harunnurrasyid \\ Sanusi
}

Pascasarjana Ilmu Komunikasi Universitas Islam Kalimantan MAB Banjarmasin

\begin{abstract}
The purpose of this study was to determine how Communication Analysis Community Empowerment Program (A Case Study Corporate Social Responsibility Education Program). The method used in this study is a qualitative research method, this method is trying to describe and explain an event by looking at the facts that exist as observations, but researcher also analyze and integrate, after that researcher conducted a classification. Data collection methods that writer use are interviews and documentaries.

These results indicate CSR Department PT. Adaro Indonesia also implements its management as POAC (Planning, Organizing, Actuating, Controlling). Fund management process of Adaro's CSR program PT. Adaro Indonesia is closely related to the district government. The results of the research, it was found that the knowledge of the community has a moderate level of knowledge on CSR
\end{abstract}

Keywords: Communication Analysis, Corporate Social Responsibility 


\section{PENDAHULUAN}

Perusahaan dalam realitasnya merupakan representasi dari institusi ekonomi. Dalam perkembangannya, keberadaan perusahaan dianggap mampu memberikan banyak kontribusi untuk masyarakat sekitar seperti terbukanya peluang dan lapangan pekerjaan, memberi donasi untuk masyarakat, tumbuhnya ekonomi masyarakat dan multiplier effect lainnya. Peranan perusahaan/sektor swasta cukup vital dalam pembangunan bidang ekonomi suatu negara maupun masyarakat.

Namun tidak dapat dipungkiri bahwa keberadaan perusahaan juga acapkali memunculkan berbagai permasalahan sosial dan lingkungan bagi masyarakat disekitarnya, khususnya perusahaan yang bergerak dalam pengelolaan sumberdaya alam/ekstraktif. Hal tersebut muncul karena sesuai karakter perusahaan yang cenderung hanya mengejar keuntungan ekonomi semata tanpa menimbang masalah ataupun dampak negatif yang ditimbulkannya. Dalam tahap ini, adanya kendali/manejemen atas operasional perusahaan untuk menciptakan keselarasan dan keseimbangan menjadi penting.

Tanggung jawab sosial perusahaan atau yang lebih populer dengan istilah Corporate Social Responsibility (CSR) merupakan tindakan yang harus diperhatikan oleh perusahaan dalam menjalankan setiap aktivitas bisnisnya.Tanggung jawab sosial berkaitan dengan tanggung jawab etis perusahaan terhadap dampak negatif lingkungan dan masyarakat (Noor Hadi, 2011:22). Dalam menjalankan aktivitas bisnisnya untuk mencapai tujuan (profit), perusahaan diharapkan untuk memperhatikan dampak lingkungan yang ditimbulkan serta dapat memberi kontribusi untuk masyarakat di sekitarnya. Peran CSR dalam hal ini adalah untuk menyelaraskan dan menyeimbangkan dampak-dampak yang ditimbulkan dari keberadaan sebuah perusahaan.Terkait peran vital yang dimiliki oleh perusahaan dalam mendukung pengembangan ekonomi suatu negara maupun masyarakat, regulasi ataupun pengaturan mengenai implementasi CSR menjadi sangat diperlukan. Di Indonesia, regulasi mengenai implementasi CSR terhadap persoalan 
sosial dan lingkungan diatur dalam Undang-Undang. Dapat dilihat pada penjelasan Undang-Undang Republik Indonesia Nomor 40 Tahun 2007 Tentang Perseroan Terbatas Pasal 74 ayat 1 :

"Ketentuan ini bertujuan untuk tetap menciptakan hubungan Perseroan yang serasi, seimbang dan sesuai dengan lingkungan, nilai, norma dan budaya masyarakat setempat. Yang dimaksud dengan "Perseroan yang menjalankan kegiatan usahanya di bidang sumber daya alam" adalah Perseroan yang kegiatan usahanya mengelola dan memanfaatkan sumber daya alam. Yang dimaksud dengan "Perseroan yang menjalankan kegiatan usahanya yang berkaitan dengan sumber daya alam" adalah Perseroan yang tidak mengelola dan tidak memanfaatkan sumber daya alam, tetapi kegiatan usahanya berdampak pada fungsi kemampuan sumber daya alam."

Penjelasan mengenai "perseroan yang menjalankan kegiatan usahanya di bidang sumber daya alam" di atas lebih ditujukan kepada perusahaan yang bergerak di bidang migas maupun tambang, sedangkan "perseroan yang menjalankan kegiatan usahanya yang berkaitan dengan sumberdaya alam" adalah perusahaan nonmigas/tambang. Namun pada hakikatnya tidak bisa dipungkiri bahwa perusahaan memanfaatkan sumber daya alam dalam aktivitas bisnisnya. Sehingga tiap-tiap perusahaan diharapkan dapat berpartisipasi dan berkontribusi dalam memikirkan keberlangsungan lingkungan baik sosial maupun alam sekitarnya. PT. Adaro Indonesia sebagai perusahaan yang bergerak di bidang pengelolaan sumber daya alam batubara memulai program CSR-nya pada tahun 1994, yaitu sejak awal beroperasinya perusahaan di Kabupaten Tabalong. Pada awal pelaksanaannya, program yang dilaksanakan masih dalam bentuk sumbangan tanpa dibekali dengan perencanaan strategis dan jangka panjang. Seiring dengan adanya peraturan/regulasi mengenai kewajiban setiap perusahaan untuk melaksanakan kegiatan CSR, kini perusahaan mulai mengembangkan kegiatan-kegiatan CSR-nya ke arah jangka panjang (pasca-tambang). Adapun tujuan utama program CSR PT. Adaro Indonesia adalah untuk menciptakan masyarakat pasca-tambang yang mandiri dan berkelanjutan. Penghargaan dalam pelaksanaan CSR merupakan 
bentuk apresiasi atas keberhasilan perusahaan dalam kegiatan pemberdayaan masyarakat sekitar melalui program CSR-nya. Pada tahun 2009 lalu, PT. Adaro Indonesia berhasil mendapatkan 4 penghargaan dalam event yang diadakan oleh CFCD (CorporateForum For Community Development) yang bekerjasama dengan Kementerian Sosial. PT. Adaro Indonesia mendapatkan peringkat Gold di bidang sosial dan lingkungan untuk program pertanian terpadu. Selang tiga tahun dalam event yang sama, PT. Adaro Indonesia juga mendapat 7 penghargaan, masingmasing tiga penghargaan Platinum, tiga penghargaan Gold dan satu penghargaan Silver untuk program pengembangan kebun karet, pembentukan kampung ternak dan koperasi wanita tani suka maju. Untuk penghargaan internasional, pada tahun 2012 yang lalu PT. Adaro Indonesia berhasil meraih Health Promotion Award yang kedua kalinya dalam ajang Asia Responsibility Entrepreneurship Award (AREA) melalui program penanggulangan buta katarak. Begitu banyaknya penghargaan yang diperoleh PT. Adaro Indonesia dalam keberhasilan kegiatan pemberdayaan masyarakat melalui program CSR menjadi menarik untuk ditelaah lebih lanjut tentang apa saja program/kegiatan yang dilaksanakan oleh perusahaan dan bagaimana dampak program CSR untuk masyarakat sehingga perusahaan mendapatkan penghargaan atas keberhasilannya dalam kegiatan pemberdayaan.

Indonesia adalah salah satu negara di dunia yang mewajibkan korporasi, khususnya yang bergerak dalam pengelolaan sumber daya alam (SDA ) agar mengeluarkan dana untuk Tanggung Jawab Sosial Perusahaan atau Corporate Social Responsibility (CSR). Peraturan perundang-undangan di Indonesia yang mengatur Corporate Social Responsibility (CSR) masuk ke dalam UU No. 40 Tahun 2007 tentang Perseroan Terbatas (UU PT) dan UU No. 25 Tahun 2007 tentang Penanaman Modal (UU PM).

Menurut Pasal 1 angka 3 UUPT, Tanggung Jawab Sosial dan Lingkungan (TJSL) adalah komitmen perseroan untuk berperan serta dalam pembangunan ekonomi berkelanjutan guna meningkatkan kualitas kehidupan dan lingkungan yang bermanfaat, baik bagi perseroan sendiri, komunitas setempat, maupun masyarakat pada umumnya. Pasal 74 UU PT yang menyebutkan bahwa setiap 
perseroan yang menjalankan kegiatan usahanya di bidang dan atau berkaitan dengan sumber daya alam wajib melaksanakan tanggung jawab sosial dan lingkungan. Jika tidak dilakukan, maka perseroan tersebut akan dikenai sanksi sesuai dengan ketentuan perundang-undangan.

Sedangkan menurut UU PM dalam Pasal 15 huruf B UU 25/2007 diatur bahwa setiap penanam modal wajib melaksanakan TJSL. Yang dimaksud dengan TJSL menurut Penjelasan Pasal 15 huruf B UU 25/2007 adalah tanggung jawab yang melekat pada setiap perusahaan penanaman modal untuk tetap menciptakan hubungan yang serasi, seimbang, dan sesuai dengan lingkungan, nilai, norma, dan budaya masyarakat setempat.

Pemberlakuan Undang-Undang tersebut pada dasarnya ditujukan untuk dapat menjadi pengikat, agar para pelaku usaha tertentu senantiasa dapat menjalankan kewajiban sosialnya. Budi Santoso selaku staf ahli Menteri Kordinator Perekonomian Bidang Pengentasan Kemiskinan mengatakan bahwa secara umum, ada empat harapan pemerintah terkait pelaksanaan CSR diantaranya: mampu mendorong ekonomi kerakyatan, dapat memberikan akses kepada masyarakat, memberikan pelayanan dasar kepada masyarakat miskin dan kelompok khusus, serta mampu meningkatkan kemampuan dan kualitas masyarakat miskin (sumber:www.republika.co.id).

Berdasarkan latar belakang diatas, maka penulis perlu meneliti tentang “Analisis Komunikasi Pada Program Pemberdayaan Masyarakat (Studi Kasus Program Corporate Social Responsibility Pendidikan PT. Adaro Indonesia)"

Penelitian ini bertujuan untuk mendeskripsikan proses perencanaan dan manajemen komunikasi yang dilakukan oleh PT. Adaro Indonesia dalam melaksanakan program CSR Pendidikan untuk masyarakat, mendeskripsikan pengelolaan dana CSR pendidikan PT. Adaro Indonesia dan mendeskripsikan masyarakat tentang CSR pendidikan PT. Adaro Indonesia.

\section{TINJAUAN TEORITIS}




\section{Teori Komunikasi}

Komunikasi menyentuh segala aspek kehidupan manusia dan menentukan kualitas hidup manusia serta mempelajari segala segi pernyataan antara manusia salah satunya komunikasi yang terjadi antara atasan dengan bawahan dalam suatu organisasi atau kantor menggunakan komunikasi untuk menyampaikan ide-ide atau nasehatnya kepada semua karyawan sehingga terjadi komunikasi timbal balik antara pimpinan/atasan dan karyawan/pegawai. Stoner dan Wankel dalam Moekijat (2003) mengemukakan bahwa komunikasi adalah suatu proses dengan mana orangorang berusaha memberikan pengertian melalui penyampaian pesan-pesan berupa lambang.

\section{Komunikasi Organisasi}

Menurut Goldhaber dalam Arni (2007: 70) komunikasi organisasi memiliki makna yaitu : "Organizational communications is the process of creating and exchanging message within a network of independent relationship to cope with environment uncertainly" Artinya, komunikasi organisasi adalah proses saling menukar pesan dalam satu jaringan organisasi yang saling ketergantung satu sama lain untuk mengatasi lingkungan yang tidak pasti.

\section{Komunikasi Eksternal}

Komunikasi eksternal ialah komunikasi antara pimpinan organisasi dengan khalayak diluar organisasi. contohnya yaitu komunikasi yang dilakukan dari instansi-instansi pemerintah maupun swasta kepada masyarakat luas. Komunikasi eksternal ini lebih banyak dilakukan oleh kepala Hubungan Masyarakat (HUMAS) dan Public Relations Officer dari pada pimpinan itu sendiri. Yang dilakukan sendiri oleh pimpinan hanyalah terbatas pada hal-hal yang dianggap sangat penting sepeti negosiasi yang menyangkut tentang kebijakan organisasi. yang lainnya dilakukan oleh kepala humas yang dalam kegiatan komunikasi eksternal merupakan tangan kanan pimpinan (Uchjana. 2007: 128).

\section{Public Relatios(PR)}


Public Relations adalah sebuah fungsi kepemimpinan dan manajemen yang membantu pencapaian tujuan sebuah organisasi, membantu mendefinisikan filosofi, serta memfasilitasi perubahan organisasi. para praktisi public relations berkomunikasi dengan semua masyarakat internal dan eksternal yang relevan untuk mengembangkan hubungan positif serta menciptakan konsistensi antara tujuan organisasi dengan harapan masyarakat. (Lattimore, Baskin, Suzatte, Heiman, Elizabeth. 2010: 4).

\section{Tujuan Public Relatios (PR)}

Pada tujuan Public Relatios terdapat beberapa pendapat Ahli, seperti menurut Dimock Marshall Cs, tujuan Public Relatios terbagi menjadi dua, yaitu secara positif dan secara defensif.

a. Secara positif

Berusaha untuk mendapatkan dan menambah penilaian dan goodwill suatu organisasi atau badan.

b. Secara defensive

Berusaha untuk membela diri terhadap pandangan masyarakat yang bernada negative, bilamana diserang, dan serangan itu kurang wajar, padahal organisasi kita tidak salah, dengan demikian tindakan ini adalah salah satu aspek penjagaan atau pertahanan.

\section{Corporate Social Responsibility}

Corporate Social Responsibility terhadap lingkungan yang pertama kali dikemukakan oleh Howard R. Bowen, dikemukakan dalam konsep cost benefit ratio versus social benefit ratio, yaitu setiap perusahaan berskala besar hendaknya jangan hanya bermotivasi mencapai profit sebesar-besarnya dengan membandingkan cost dan benefit (least cost combination), tanpa sama sekali melihat ratio antara cost dengan social benefit (manfaat sosial), keberadaan perusahaan terhadap lingkungan. Diingatkan, jangan sampai perusahaan berskala besar menjadi enclave (pulau) di tengan-tengah samudra kemiskinan, atau perusahaan tidak mampu menjadi sentral pertumbuhan ekonomi lingkungan. Menjadikan 
perusahaan berskala besar menjadi pusat pertumbuhan dan perkembangan lingkungan merupakan tanggung jawab sosial perusahaan berskala besar (Ardianto. 2011: 39-40).

Lain lagi menurut The World Bussiness Council For Sustainable Development (WBCSD) yaitu lembaga yang menangani permasalahan keberlangsungan usaha perusahaan yang mendefinisikan Corporate Social Responsibility yaitu :

"Continuing commitment by business to behave ethically and contribute to economic development while improving the quality of life of the workforce and their families as well as of the local community and society at large"

\section{METODE PENELITIAN}

Tujuan dari penelitian ini adalah ingin mengetahui kegiatan pemberdayaan yang dilakukan oleh PT. Adaro Indonesia melalui program CSR-nya serta bagaimana dampak dari kegiatan tersebut bagi masyarakat sekitar tambang dan perusahaan. Berpijak dari tujuan tersebut, jenis penelitian yang digunakan dalam penelitan ini adalah kualitatif. Hal tersebut di dasarkan pada pertimbangan : Pertama, menyesuaikan metode kualitatif lebih mudah apabila berhadapan dengan kenyataan jamak. Kedua, metode ini menyajikan secara langsung hakikat hubungan antara peneliti dan responden. Ketiga, metode ini lebih peka dan lebih dapat menyesuaikan diri dengan banyak penajamakan pengaruh bersama terhadap polapola nilai yang dihadapi (Moeloeng, 1994:9-10).

Jenis penelitian ini adalah kualitatif deskriptif dengan aliran konstruktivisme. Dalam Aditya (2011:32), Moeloeng (2005:6) menyebutkan penelitian kualitatif adalah penelitian yang bermaksud untuk memahami fenomena tentang apa yang dialami oleh subjek penelitiannya misalnya perilaku, persepsi, motivasi, tindakan, secara holistik, dan dengan cara deskripsi dalam bentuk kata-kata dan bahasa, pada suatu konteks khusus yang alamiah dan dengan memanfaatkan berbagai metode ilmiah.

Penelitian deskriptif kualitatif bertujuan untuk mendeskripsikan apa-apa yang saat ini berlaku. Di dalamya terdapat upaya mendeskripsikan, mencatat, 
analisis, dan menginterpretasikan kondisi yang sekarang ini terjadi atau ada. Menurut Sugiyono (2011), berdasarkan tingkat eksplanasinya, penelitian deskriptif dilakukan untuk mengetahui nilai variabel mandiri, baik satu variabel atau lebih (independen) tanpa membuat perbandingan, atau menghubungkan dengan variabel yang lain.

\section{HASIL DAN PEMBAHASAN}

Hasil penelitian tentang Analisis Komunikasi Pada Program Pemberdayaan Masyarakat (Studi Kasus Program Corporate Social Responsibility Pendidikan PT. Adaro Indonesia) yang meliputi perencanaan dan manajemen sebagai proses mencapai tujuan yang diharapkan. Pertanyaan-pertanyaan yang disampaikan dalam wawancara ini dari segi perencanaan (planning) ialah mengenai perencanaan kegiatan, perencanaan pesan dan perencanaan media, sedangkan dari segi manajemen mengenai pengawasan dan pengorganisasianya dalam Analisis Komunikasi Pada Program Pemberdayaan Masyarakat (Studi Kasus Program Corporate Social Responsibility Pendidikan PT. Adaro Indonesia). Waktu pelaksanaan selama 5 bulan lamanya sejak bulan Januari 2018 hingga bulan Mei 2018. Hasil penelitian ini diperoleh dengan teknik wawancara dengan informan dalam bentuk observasi langsung dan apabila data yang diperlukan sudah terkumpul kemudian dianalisis. Analisis ini sendiri terfokus pada Analisis Komunikasi Pada Program Pemberdayaan Masyarakat (Studi Kasus Program Corporate Social Responsibility Pendidikan PT. Adaro Indonesia), yang dikaitkan kepada beberapa unsusr atau identifikasi masalah. Selain itu juga peneliti melakukan wawancara dengan informan pendukung yaitu penerima bantuan CSR Pendidikan guna melengkapi data pendukung mengenai Analisis Komunikasi Pada Program Pemberdayaan Masyarakat (Studi Kasus Program Corporate Social Responsibility Pendidikan PT. Adaro Indonesia).

\section{Pembahasan}


Dalam pencapaian CSR Pendidikan, perlu diperhatikan pada tahap penentuan tujuan dalam membentuk perencanaan, hal ini berkaitan dengan komponen-komponen yang hendak digunakan dalam pelaksanaan rencana tersebut. Dengan adanya kesesuaian antara komponen-komponen dengan tujuan rencana maka akan membuat pencapaian tujuan tersebut berjalan dengan efektif. Sehingga bisa dikatakan bahwa efektifitas suatu strategi Public Relations ditentukan pada tahap perencanaannya.

Menurut hasil wawancara dengan Idham Kurniawan CSR Department Head dan Government \& Media Relantions Departement Head Dalam melaksanakan tugasnya, harus melakukan usaha yang dilakukan dengan sengaja, direncanakan dan dilakukan terus-menerus untuk mendapatkan dan menjalin saling pengertian antara satu organisasi. Untuk mencapai itu semua kita memerlukan keterbukaan terhadap kebutuhan-kebutuhan yang diperlukan serta kemampuan untuk mendengarkan, kesabaran, mau menerima kritik, serta mampu memberikan jalan keluar dan masalah yang dialami dalam melaksanakan kegiatan CSR Pendidikan.

Perencanaan adalah segala sesuatu yang akan atau harus dilakukan itu diupayakan secara sistematis dan dinyatakan secara tertulis. Pada dasarnya perencanaan adalah suatu proses atau usaha tindakan membuat rencana. Tindakantindakan yang dilakukan dalam membuat suatu perencanaan tidak lain adalah tindakan pengambilan keputusan mengenai apa yang akan dan harus dilakukan. Kemudian merumuskan kegiatan-kegiatan yang diusulkan untuk mencapai tujuan yang diharapkan. Perencanaan Komunikasi sangat diperlukan dan dibutuhkan sebelum kita melakukan kegiatan dan turun ke lapangan untuk melakukan suatu observasi. Berdasarkan buku Prof. H.Hafid Cangara, M. Sc. Ph. D, komunikasi yang dilaksanakan tidak luput dari berbagai rintangan atau hambatan. Sejauh ini perencanaan yang dilakukan Departemen CSR Adaro dibagi menjadi tiga bagian yaitu. Perencanaan kegiatan, Perencanaan Pesan dan Perencanaan media.

Program CSR mengharuskan pengawasan oleh pihak yang ditetapkan oleh bupati. Pengawasan tersebut dilaksanakan oleh sebuah tim pengawas yang terdiri dari para camat dimana program CSR tersebut dilaksanakan. 
Pengawasan terhadap program CSR yang tidak optimal menjadi salah satu faktor program CSR pendidikan tidak berdampak bagi peningkatan kualitas pendidikan. Schick (1978) mengungkapkan bahwa pengawasan terhadap anggaran untuk menjamin tidak terjadi pemborosan dan salah kelola terhadap dana yang telah dialokasikan. Pengawasan merupakan upaya pencegahan terhadap penyelewengan serta kelebihan pengeluaran. Pada program CSR pendidikan PT. Adaro Indonesia, pengawasan dilakukan oleh PT. Adaro Indonesia yang juga bertindak sebagai pelaksana program. Pengawasan tersebut tidak efektif karena pengawas bukan pihak yang independen yang terpisah dari struktur perusahaan atau pelaksana program. Pada tataran tertentu, pengawasan oleh pelaksana program CSR dapat menjamin alokasi telah digunakan sesuai dengan distribusinya, tetapi pada sisi lain pengawasan oleh pelaksana program sangat sulit menjamin tidak adanya praktik manipulasi dalam penggunaan anggaran.

Persepsi masyarakat terhadap PT. Adaro Indonesia cukup baik. Ditegaskan oleh salah seorang informan pendukung bahwasannya kehadiran PT. Adaro Indonesia sangat memberikan keuntungan bagi masyarakat Tabalong untuk program CSR yang selama ini telah diberikan oleh PT. Adaro Indonesia. Semua kebutuhan masyarakat tabalong yang diajukan kepada perusahaan sering kali di acc dan jarang sekali ditolak. Sama halnya dengan pendapat informan pendukung, beliau menanggapi positif tentang keberadaan PT. Adaro Indonesia. Perusahaan peduli kepada masyarakat dan apapun yang diminta masyarakat sering diberikan. Khususnya mengenai CSR Pendidikan yang diberikan setiap tahunnya.

\section{KESIMPULAN}

Berdasarkan paparan hasil penelitian pada Bab V, maka penulis sampaikan beberapa kesimpulan sebagai berikut:

1. Dalam segi perencanaan dan manajemen komunikasi Departement CSR menunjukan bahwa Program Pemberdayaan Masyarakat ( Study Kasus Program Corporate Social Responsibility Pendidikan PT. Adaro Indonesia) mempunyai tujuan yang diharapkan dapat mencapai suatau hasil yang baik, kemudian melakukan kegiatan sesuai dengan perencanan kegiatan untuk 
menyampaikan pesan yang tentunya melalui media untuk mendukung kegiatan yang sudah dilakukan. Departement CSR PT. Adaro Indonesia pun menerapkan manajemennya sebagai POAC (Planning, Organizing, Actuating, Controlling).

2. Proses pengelolaan dana program CSR Adaro PT. Adaro Indonesia sangat terkait dengan pemerintah kabupaten. Program yang akan dilaksanakan harus melalui proses pembahasan dan diputuskan oleh sebuah tim perumus yang dibentuk oleh bupati. Sebagai awal dalam proses perencanaan ditingkat kabupaten, pihak CSR PT. Adaro menghimpun data usulan/usulan program dari masyarakat serta hasil musyawarah perencanaan pembangunan ditingkat desa sampai kabupaten. Berbagai usulan masyarakat tersebut menjadi bahan penyusunan draft program CSR oleh Departemen CSR PT. Adaro Indonesia. Draft program itu dibahas dalam tim perumus kabupaten yang diketuai oleh sekretaris daerah kabupaten dan beranggota para kepala dinas di Kabupaten Tabalong. Tim Perumus menetapkan persentasi alokasi bidang CSR berdasarkan kebijakan kabupaten. Keputusan rapat tim perumus kemudian dituangkan dalam bentuk SK Bupati yang menjadi dasar seluruh penggunaan dana CSR PT. Adaro Indonesia di kabupaten.

3. Dari hasil penelitian diperoleh bahwa pengetahuan masyarakat memiliki tingkat pengetahuan sedang tehadap CSR. Dari hasil penelitian, masyarakat yang selama ini menerima program CSR yang sudah berjalan selama bertahuntahun masih tidak mengetahui istilah dari CSR. Kebanyakan mereka mengetahui bahwa CSR adalah bantuan. CSR dan bantuan adalah hal yang berbeda. Bantuan adalah salah satu wujud dari CSR. Sedangkan CSR sendiri tidak sekedar bantuan yang bersifat cash tetapi memiliki prinsip suistanability, accountability dan transparency. Sehingga perlu adanya tindakan sosialisasi mengenai CSR agar masyarakat tidak menyamakan CSR dengan bantuan. Sosialisasi tidak hanya sekedar tokoh masyarakat dan karang taruna saja, melainkan masyarakat yang juga mendapatkan dan merasakan program CSR secara langsung. 


\section{Saran}

Berdasarkan pengalaman penulis dalam melakukan penelitian maka penulis memberikan saran sebagai berikut:

1. Karena perusahaan telah lama berdiri dan banyak mendapatkan keuntungan/laba kepada pengusaha disarankan mempertimbangkan untuk lebih meningkatkan tanggung jawab sosial perusahaan terhadap masyarakat sekitar perusahaan dari berbagai aspek materi maupun non materi. Dukungan dari masyarakat sangatlah penting bagi majunya perusahaan dan merupakan faktor penggerak dari kelangsungan bisnis perusahaan ini.

2. Peningkatan hubungan antara perusahaan dengan pemerintah, termasuk dalam adanya informasi atau perencanaan dari kedua belah piak atas suatu sasaran sehingga pelaksanaan CSR menjadi efektif dan berkesinambungan.

3. Penelitian ini masih memiliki beberapa kelemahan dalam analisis, maka disarankan pada peneliti selanjutnya dapat dilengkapi dengan pelaksanaan observasi yang lebih baik lagi demi kemajuan perusahaan dalam mensukseskan program CSR Pendidikan.

4. Dapat dijadikan sebagai bahan informasi terkait dengan CSR dan dapat menambah wawasan dan kepustakaan bagi pihak-pihak yang berkepentingan.

\section{Daftar Pustaka:}

\section{Buku:}

Bungin, Burhan. 2011. Metodologi Penelitian Sosial : Format-Format Kuantitatif dan Kualitatif. Surabaya: Airlangga University Press

Caroll, AB. 2003. Bussiness and Society, Ethics and Stakeholder Managament. SoauthWestern: Thomson

Caroll, Archie B. 2008. A Three Dimensional Conceptual Model of Corporate Performance. Crowther, David \& Aras, Guler. 2008. Corporate Social Responsibility. Ventu Publishing Aps ISBN 978-87-7681-415-1

Devito, Joseph A. 2011. Komunikasi Antarmanusia Edisi Kelima. Jakarta: Karisma Publishing.

Hadi, Nor. 2014. Corporate Social Responsibility. Yogyakarta: Graha Ilmu ISBN 978979-756-712-5

Hermawan, Agus. 2012. Komunikasi Pemasaran. Jakarta: Penerbit Erlangga 
Kriyantono, Rachmat. 2014. Teknik Praktis Riset Komunikasi. Jakarta: Kencana Prenadamedia Group ISBN 979-3925-62-0

Miles, Matthew B, A. Michael Huberman dan Johnny Saldana. 2014. Qualitative Data Analysis, A Methods Sourcebook Edisi Ketiga. Sage Publications: Inc.

\section{Skripsi \& Tesis}

Aditya, Dadang Azwar. 2011. Impementasi CSR terhadap Perusahaan. Universitas Negeri Semarang

Afdilah, Nur Hasnah. 2014. Strategi Komunikasi Pembangunan dalam Community Development (Studi Deskriptif Kualitatif pada Seksi Kebersihan dan Lingkungan Hidup Dusun Sukunan Banyuraden Gamping Sleman Yogyakarta). Universitas Islam Negeri Sunan Kalijaga

Asy'ari, Hasan. 2009. Implementasi CSR sebagai Modal Sosial pada PT. Newmont. Semarang: Universitas Diponegoro

Dewani, Anggary Pasha. 2009. Kebijakan, Implementasi, dan Komunikasi CSR PT. Indocement Tunggal Prakarsa, Tbk. Institut Pertanian Bogor

Heriyanto. 2014. Persepsi Masyarakat terhadap Kualitas Pelayanan Publik pada Bagian Administrasi Kesejahteraan Rakyat Pemerintah Kabupaten Gunung Kidul DIY. Universitas Negeri Yogyakarta

Muchlis, Fuad. 2009. Analisis Komunikasi Partisipatif dalam Program Pemberdayaan Masyarakat (Studi Kasus pada Implementasi Musyawarah dalam PNPM Mandiri Perdesaan di Desa Teluk Kecamatan Pemayung Kabupaten Batang Hari). Institut Pertanian Bogor

Rahmawati, Annisa. 2010. Efektivitas Organisasi dan Implementasi Program CSR PT. Indocement Tunggal Prakarsa TBK. Institut Pertanian Bogor.

\section{Jurnal}

Carrol \& Shabana. 2010. The Business Case for CSR: A Review of Concepts, Research, and Practice. International Journal of Management Reviws British Academy of Management DOI: 10.1111/j.1468-2370.2009.00275.x

Crane, Williams, Matten, Moon, \& Siegel. 2008. The Corporate Social Responsibility Agenda. The Oxford Handbook of CSR DOI: 10.1093/oxfordhb/9780199211593.003.0001

Gond, Kang, Moon. 2010. Corporate Social Responsibility and Government in Western Europe and Northeast Asia from a National Governance Systems Perspective. Research Paper Series ISSN 1497-5124 Nottingham University

\section{Publikasi Lainnya}

Awza, Lubis, \& Rasyid. 2015. Analisis Komunikasi dalam Pemberdayaan Masyarakat pada Program Kemitraan PTPN $V$ di Pekanbaru. Seminar Nasional: Politik, Birokrasi, dan Perubahan Sosial ke-II "Pilkada Serentak, Untung Rugi, dan Korupsi Politik". Pekanbaru

Badan Pusat Statistik Kota Batam. Indeks Pembangunan Manusia Kota Batam. No. Publikasi 2171.15.04 No Katalog BPS 4102002.2171

Cholisin. Pemberdayaan Masyarakat. Gladi Manajemen Pemerintahan Desa Bagi Kepala Bagian Uursan Hasil Pengisian di Sleman, Desember 2011. Yogyakarta 
Hadi, Agus Purbathin. 2007. Konsep Pemberdayaan, Partisipasi, dan Kelembagaan dalam Pembangunan. Yayasan Agribisnis/Pusat Pengembangan Masyarakat Agrikarya (PPMA)

Indonesia Sanitation Sector Development Program. 2010. Buku Panduan Tanggung Jawab Sosial Perusahaan ISO 26000. Guidance on Social Responsibility. Committee Draft

Kementrian Lingkungan Hidup. 2012. Petunjuk Pelaksanaan CSR Bidang Lingkungan.

Ramah, Muchri. Komunikasi Pembangunan dalam Perspektif Terkini. ISSN 14113341

Sultan, M. Iqbal. Perspektif Teoritis Komunikasi Pembangunan. Bengkel Komunikasi Pembangunan Efektif-Bursa Pengetahuan Kawasan Timur Indonesia Juni 2011. Makassar.

UNDP. 2002. United Nations Development Programme: Millennium Development Goals (MDGs). 